\title{
Dos Açougues aos Frigoríficos Uma História Social do Trabalho na Produção de Carne, 1750 a 1950
}

\author{
From Butchers to Slaughterhouses: \\ A Social History of The Labor in Meat Production, 1750 to 1950
}

\author{
Antônio de Pádua Bosi*
}

\begin{abstract}
Resumo
Este artigo discute o trabalho e os trabalhadores envolvidos no processo histórico que instituiu os matadouros públicos, reformulou a atividade dos açougueiros e estruturou a produção industrial da carne em frigoríficos. O estudo cobre o período de 1750 a 1950 e examina este processo na Europa e nos EstadosUnidos.Oargumento principal mostracomoaindustrialização dacarne esteve articulada com a simplificação e divisão do trabalho do açougueiro, que forneceuabasetécnicaparaaorganizaçãodoprocessamentodacarneemescala. Palavras-chave: Frigoríficos. Matadouros. Açougueiros.
\end{abstract}

\begin{abstract}
This paper discusses the labor and the workers linked to the historical process which established the Public Slaughterhouses, reorganized butchers' activity and also structured the industrial production of meat. The research includes the period 1750-1950 and examines this process in Europe and in the United States. The main argument shows how the industrialization of meat was linked with the simplification and division of the labor of butchers, and how it provided the technical basis for the organization of the processing of meat in large scale.
\end{abstract}

Keywords: Slaughterhouses. Abattoir. Meatpacking plants. Butchers.

Certamente a sociedade desencoraja assuntos do tipo entender como a carne chega do abatedouro dentro dessas embalagens de isopor, seladas com etiquetas de peso, preço e informação sobre o produto, picadinha, impossível de reconhecer... principalmente enquanto se come carne. ${ }^{1}$

\footnotetext{
*É professor associado da Universidade Estadual do Oeste do Paraná e doutor em História pela UFF. Este texto apresenta resultados parciais de pesquisa desenvolvida com apoio material e financeiro do CNPq. Agradeço aos pareceristas pelas recomendações que deixaram o texto mais claro.E-mail: antonio_bosi@hotmail.com 1 SACCO, Joe. Derrotista. São Paulo: Editora Conrad, 2006. p. 56.
} 


\section{INTRODUÇÃO}

Até o século XVIII o consumo de carne na Europa e nas Américas era esporádico, na maioria das vezes decorrente da criação doméstica de animais e da caça. A venda de carne existia basicamente nos centros urbanos e não era uma prática ao alcance de todos. Tratava-se de um artigo de luxo, e até mesmo os trabalhadores mais especializados tinham dificuldade em comprá-lo. Nas grandes cidades, a exemplo da Londres dos séculos XVII e XVIII, apenas os tipos inferiores de carne como "arenque defumado e salgado, pés de carneiro e de vaca, orelhas de porco, miúdos, tripas e morcela" ${ }^{2}$ cabiam no orçamento dos trabalhadores.

No que se refere à produção de carne era um negócio restrito ao ofício dos açougueiros, regulamentado por legislação específica das corporações e realizado com base em trabalho artesanal pouquíssimo dividido. ${ }^{3}$ Aliás, a divisão do trabalho típica da manufatura não penetrou no mundo dos açougueiros antes da instituição dos frigoríficos ao longo do século XIX e da primeira metade do século XX.

A literatura especializada no assunto tem sustentado uma hipótese que busca explicar esta mudança. Evidencia-se que tal situação alterou-se a partir de intervenções higienistas e humanizadoras mais sistemáticas e invasivas do Estado no abate de animais. ${ }^{4}$ Reconhecendo a força desta hipótese e nela apoiado, tento discutir o trabalho dos açougueiros e sua organização em guildas. Em seguida, busco identificar e explicar o processo histórico que instituiu os matadouros públicos e reformulou o trabalho dos açougueiros. Por último, tento explorar a produção industrial da carne como a responsável pela liquidação do domínio e da existência dos açougueiros.

\section{TRABALHO DOS AÇOUGUEIROS NA EUROPA PRÉ-INDUSTRIAL}

A corporação dos açougueiros edificada em 1527 na cidade de Hildesheim, norte da Alemanha, é uma das mais emblemáticas evidências do esplendor vivido por este ofício. Este prédio tinha sete andares e sua altura chegava aos 26 metros. Sua porta, por onde passavam os animais que seriam abatidos lá dentro, media aproximadamente 2,5 metros,

2 THOMPSON, E. A Formação da Classe Operária Inglesa. 2. Ed. Rio de Janeiro: Paz e Terra, v. 2, 1988. p.179. 3 EPSTEIN, S. R. Craft Guilds. Apprenticeship and Technological Change in Preindustrial Europe. The Journal of Economic History, Cambridge, v. 58, n. 3, 1998. p. 684-713.

4 LEE, P. Y. (Org.). Meat, Modernity, and the Rise of the Slaughterhouse. Durham, New Hampshire: University of New Hampshire Press, 2008. 
e as paredes, com uma espessura de 1,5 metros, garantiam uma ótima refrigeração para a carne.

Guildas como a de Hildesheim, bem estruturadas, serviam como mercado de venda da carne. Lá dentro bois, porcos, ovelhas e cavalos eram abatidos, eviscerados, cortados e preparados para a venda no local ou em outros mercados distantes. Os açougueiros associados à corporação exerciam o controle sobre a produção. A definição das regras sobre a qualidade e dos preços da carne também estava sob o domínio das corporações, o que gerava muitos conflitos entre os mestres de ofício e os representantes da municipalidade ou do próprio Rei.

Esta tensão parece ter sido mais presente do que geralmente tendemos a acreditar quando pesquisamos os registros deixados pelas guildas, mesmo porque os privilégios detidos por açougueiros dependiam de algum tipo de confirmação feudal. Os atritos gerados nesta fronteira política podiam, inclusive, transbordar e atingir níveis incontornáveis, como foi o caso da rebelião de 1413, em Paris (acontecida no contexto da Guerra dos Cem Anos), que tentou evitar a elevação da carga fiscal pelo reinado de Carlos VI. Ela foi liderada por açougueiros, peleiros e curtidores, e resultou na expropriação dos pertences dos açougueiros, na revogação de seus privilégios e na demolição dos abatedouros que ficavam localizados próximos à catedral de Notre Dame. ${ }^{5}$ Negociar carne não era uma prática de livre mercado.

Para a historiadora Sydney Watts, açougueiros como aqueles que patrocinaram a revolta de 1413 representavam uma força social e econômica que foi arrasada com a destruição de suas lojas, mas que retornaria à tona porque seu trabalho não podia ser substituído e nem completamente controlado pelo Estado. ${ }^{6}$ Os açougueiros tendiam a concentrar seus abatedouros em locais comuns, como a corporação de Hildesheim, e a empregar o trabalho de aprendizes e jornaleiros para tarefas constituídas numa rudimentar divisão do trabalho. Encerrados no abatedouro, esses trabalhadores se revezavam nas atividades de matar os animais, eviscerá-los, esfolá-los, executar os cortes, preparar a carne para a venda, e por vezes fervê-la para produzir salsichas.

5 ROSS, L. B. Anger and the City: Who was in charge of the Paris cabochien Revolt of 1413? In: CLASSEN, Albrecht (Org.). Urban Space in the Middle Ages and Early Modern Age. Berlim: De Gruyter, 2009. p. 433-461. 6 WATTS, Sydney. The Grand boucherie, the "right" to meat, and the growth of Paris". In: LEE, P. Y. (Org.). Meat, Modernity, and the Rise of the Slaughterhouse. Durham, New Hampshire: University of New Hampshire Press, 2008. p. 13-26. 
De maneira semelhante a outros ofícios e oficinas, o trabalho era organizado e planejado pelo mestre, que manejava o conhecimento acerca do abate, dos tipos de corte, das ferramentas, enfim, de todo o processo de trabalho. ${ }^{7}$ Havia uma distância social e econômica entre os mestres, de um lado, e os aprendizes e jornaleiros, de outro. Sem o trabalho destes últimos não seria possível aos açougueiros acumular alguma riqueza.

Embora atualmente haja um padrão de higiene que nos leva a interpretar o trabalho com carne e sangue como uma tarefa difícil e suja, antes do século XIX este não era exatamente um sentimento disseminado e consensual. Diferentemente disso, os açougueiros gozavam de certo prestígio derivado de seu ofício e, por vezes, eram temidos devido à habilidade que exibiam no uso de facas. Entretanto, esta não era a situação de aprendizes e jornaleiros.

Os aprendizes e jornaleiros realizavam tarefas difíceis e pesadas, como o abate e a limpeza das carcaças, e isto não era simples de se aprender. 0 método de abate, por exemplo, era tão mais complicado quanto maior fosse o tamanho do animal. Geralmente um boi deveria ser morto com um machado, mas isso nem sempre acontecia sem transtornos. ${ }^{8}$ Um golpe mal executado deixava o boi em agonia, e muitas vezes o aprendiz ou o jornaleiro golpeava seguidamente o animal sem qualquer sucesso. Tal técnica foi lentamente substituída desde o final do século XVIII, cedendo espaço para o "ritual judeu" - o boi tinha uma das patas traseiras presas e suspensas por correntes, era amarrado e imobilizado pela cabeça para que fosse sangrado no pescoço. ${ }^{9}$

Eviscerar e esfolar o animal também eram tarefas ingratas que exigiam força e destreza. Já o corte da carne ficava reservado ao açougueiro, mas também podia ser executado por jornaleiros e aprendizes habilidosos. A jornada de trabalho era longa, principalmente quando o trabalho envolvia a produção de salsichas, e a paga não tornava este ofício imediatamente sedutor. Os aprendizes, como era o costume, trocavam seu trabalho pelo conhecimento, pela expectativa de se tornarem mestres, e por comida e abrigo (não necessariamente nesta ordem). Os jornaleiros recebiam algum dinheiro

7 ROSSER, Gervase. Crafts, guilds and the negotiation of work in the medieval town. In: Past and Present, v. 154, 1997. p. 3-31.

8 MACLACHLAN, Ian. Humanitarian reform, slaughter technology, and butcher resistance in nineteenthcentury Britain. In: LEE, P. Y. (Org.). Meat, Modernity, and the Rise of the Slaughterhouse. Durham, New Hampshire: University of New Hampshire Press, 2008. p.107-126.

9 BRANTZ, Dorothee. Stunning Bodies: Animal Slaughter, Judaism, and the Meaning of Humanity in Imperial Germany. In: Central European History, v. 35, n. 2, 2002. p.167-194. 
que podia vir junto com alimentação e pouso, além da possibilidade de tornarem-se açougueiros.

Por fim, um mesmo açougueiro com capacidade de empregar trabalhadores não o fazia em grande número, dificilmente ultrapassando três ou quatro. De qualquer modo, fosse um ofício realizado pelos mestres, aprendizes ou jornaleiros, a habilidade era uma requisição imprescindível. Uma faca manuseada com desleixo, desatenção, desgoverno ou com pouco domínio resultava, não raras vezes, em violentos talhos no próprio corpo. Certamente a escolha de São Bartolomeu para ser santo padroeiro do ofício relacionava-se ao fato de ter este apóstolo sido supliciado com o esfolamento da pele de todo o corpo, antes de ser decapitado. Ninguém melhor do que São Bartolomeu para se identificar com a dor e o sofrimento dos açougueiros. Sua proteção era sempre bem-vinda.

A situação dos aprendizes e jornaleiros entrosados com este ofício não diferia do contexto vivido em outros ofícios. Não jantavam à mesa do mestre e de sua família. Não eram tratados com gentileza. Dormiam nas dependências dos abatedouros. Comiam sobras, embora o trabalho com a carne lhes permitisse alguma regalia proteica. Enfim, tudo servia para fixar a distância social de seu "patrão": o saber referente ao ofício, a obediência aos comandos do mestre, a dependência do aprendizado, o impedimento de participar das guildas. Mas as portas para escapar dessas condições não eram impossíveis de se destrancar.

O historiador Gervasse Rosser afirma que jornaleiros ou aprendizes já "titulados" podiam abrir pequenos abatedouros em nome de seus mestres, uma espécie de filial. Além disso, dois ou mais jornaleiros podiam constituir um tipo de confederação para reunir capital e abrir eles mesmos um abatedouro ou, "onde isto fosse proibido para não mestres, conseguir autorização para um deles poder comprar o ingresso na corporação de modo que os outros pudessem dividir seus privilégios por procuração". ${ }^{10}$ Jornaleiros e aprendizes não raramente se organizavam em confrarias ou irmandades religiosas para evitar uma exploração desmedida dos mestres e também para contar com alguma proteção em situações de dificuldade. Tais confrarias recolhiam e administravam recursos financeiros que geralmente tinham emprego certo para socorrer seus associados, mas não é o caso de vermos tais organizações como protossindicais, embora elas fossem gestadas em meio à experiência de desigualdade econômica, social e política relativamente aos mestres.

10 ROSSER, Gervase. Crafts, guilds and the negotiation of work in the medieval town. In: Past and Present, v. 154, 1997. p. 3-31p.16. 
Não obstante esta imagem histórica bastante verdadeira, o que predominava na realidade deste ofício não eram mestres ajudados por aprendizes e jornaleiros. Pesavam majoritariamente no panorama histórico pré-industrial deste ofício milhares de açougueiros que trabalhavam sozinhos em suas bancas ou pequenas lojas (localizadas nas grandes cidades) e ocupando, quando muito, um aprendiz.

A produção em escala industrial, baseada na divisão do trabalho, não foi um produto deste ofício e nem do seu tempo. Se pudéssemos nos referir a um retrato que mostrasse os principais traços constitutivos da produção e do comércio da carne no período pré-industrial europeu veríamos açougueiros avulsos, trabalhando em pequenas bancas, ora concentradas num mesmo local, ora dispersas pela cidade. De qualquer modo, reunidos ou espalhados, estes pequenos abatedouros necessitavam estar próximos do centro urbano, contar com água corrente e dispor de espaço para negociar e manter os rebanhos a serem abatidos. É bastante representativo desta realidade mercados de carne estabelecidos desde a baixa Idade Média e povoados de pequenas bancas e lojas de açougueiros. ${ }^{11}$

Mais do que em outros ofícios o conhecimento necessário à lida com a carne permanecia sob o domínio do mestre, com rala divisão de trabalho e escassa transferência de saberes para jornaleiros e aprendizes. Além disso, as tecnologias e as técnicas relacionadas ao abate, ao esquartejamento e ao preparo da carne para a venda pouco mudaram durante os dez séculos que antecederam o século XIX. Ao longo desse tempo, os açougueiros sedimentaram seu ofício e seu lugar nas principais cidades da Europa, movimentando grandes quantidades de gado, porcos, ovelhas, e abastecendo de carne a população em condições de comprá-la. Como em qualquer outro ofício havia mestres melhor posicionados economicamente do que seus pares, mas sua importância social se revelava a partir de sua identidade expressa pelo trabalho, e tal identidade era basicamente cultivada e reproduzida nas guildas.

A rigor, as corporações de ofício não eram associações de natureza estritamente profissional, cujos objetivos se resumiam em regulamentar e fiscalizar o trabalho de modo a controlar o mercado a ele relacionado. Tais finalidades são bastante conhecidas, mas não traduzem completamente a função social e política que muitas corporações se viam investidas. Mais especificamente, pode-se dizer a este respeito que a identidade pela qual os açougueiros se projetavam era cunhada e nutrida nas corporações e a partir delas.

11 MACLACHLAN, Ian. A bloody offal nuisance: the persistence of private slaughter-houses in nineteenthcentury London. In: Urban History, v. 34, n. 2, 2007. p. 227-254. 
As guildas funcionavam principalmente para chancelar determinadas relações de poder entre os açougueiros e seus subalternos, e entre os primeiros e o restante da sociedade estamental. ${ }^{12}$ De um ponto de vista geral, este tipo de relação encontrava respaldo porque estava internalizada profundamente nos próprios açougueiros e naqueles com os quais mantinham contato no cotidiano; e o reconhecimento desta simbologia particular era consensual. Assim, as corporações dos açougueiros cumpriram tanto a função de resguardar a autonomia do ofício aos mestres quanto de disseminar e sancionar, a priori, o respeito social pretendido pelos açougueiros.

Pelo menos um fato importante decorre desta conjuntura histórica. O trabalho exercido pelos açougueiros era autônomo, controlado e organizado pelo próprio executante, o que em larga medida lhe garantia uma posição de independência frente ao complexo, intrincado e emaranhado mundo feudal. Isto repercutia no valor que os mestres atribuíam ao trabalho. Na maioria dos ofícios pode-se dizer que a satisfação advinha do trabalho (do domínio sobre o processo técnico e do prestígio derivado deste), e não da renda ou da "salvação eterna", mesmo que, do ponto de vista social e político, os mestres tivessem que negociar sua presença e seus privilégios com as autoridades situadas acima deles, quaisquer que fossem elas.

Mas, do ponto de vista econômico, parte de seu trabalho não era devida por obrigação aos senhores feudais ou à Coroa do mesmo modo que as famílias camponesas se viam obrigadas a entregar parcela de sua produção aos seus suseranos. Esta zona de autonomia era bem mais ampla do que se costuma pensar. A imagem que Marx consagrou à base técnica da manufatura assentava-se neste monopólio do saber mantido sob a tutela e o controle dos mestres. Vez ou outra os limites de um ofício eram sentidos como ameaças pelas autoridades e testados, sem, contudo, serem corroídos ou cancelados, o que ratifica esta imagem: sua autonomia era um obstáculo também ao capitalismo, uma defesa "contra qualquer intrusão do capital mercantil, a única forma livre de capital" naquele tempo. ${ }^{13}$ Enfim, ter efetivo domínio sobre seu trabalho constituía parte fundamental da existência dos mestres e, em menor grau, dos jornaleiros. Este movimento recorrente em toda a Idade Média europeia demonstra como as "artes" cruzaram séculos com nítida independência numa sociedade em que as relações de produção prevalecentes eram tipicamente feudais e fundavam-se na coerção e na dependência pessoal.

12 BLACK, Antony. Guilds and Civil Society in European Political Throught from the Twelfth Century to the Present. Ithaca: Cornell University Press, 1984.

13 MARX, Karl. O Capital. Livro 1, v. 1. 3. ed. São Paulo: Abril Cultural, 1988. p.269. 
Contudo, a partir do século XVIII, esta estabilidade ficaria cada vez mais comprometida porque a realização desse trabalho, antes absolutamente visível e exposta, passou a ser interpretada como ultrajante e repulsiva. Até então sua existência esteve enraizada e sintonizada com determinada estética, e com costumes e padrões de higiene que tornavam sua presença não só tolerada como também normal. A pressão sobre esses costumes e padrões afetaria diretamente os açougueiros e seu trabalho. Junto com as cidades e os costumes, suas práticas seriam duramente atacadas e modificadas.

\section{DOS AÇOUGUES AOS MATADOUROS PÚBLICOS}

Em carta enviada ao irmão, em 1824, o escritor Thomas Carlyle descreveu o Mercado de Carne de Smithfield, na cidade de Londres:

Outro dia passei, por acaso, no mercado de Smithfield (...). Eu subi os degraus de uma porta e olhei em volta, um espaço irregular de aproximadamente trinta hectares de extensão, cercado de velhas casas de tijolo e cruzado de currais de madeira para gado. Que cena! Inumeráveis cabeças de bois gordos, amarrados em longas fileiras ou trotando para diversos dos matadouros que ali havia; e milhares de criadores de gado, vaqueiros, açougueiros, corretores de gado empurrando aqueles infelizes animais; correndo pra lá e pra cá, numa grande confusão, gritando, brigando e xingando em meio à chuva, como a imaginação não pode retratar..$^{14}$

A imagem retratada por Carlyle não deixa de ser impressionante. No fundo de sua observação estava um questionamento sobre a grande confusão estabelecida pela concentração de açougueiros cuja atividade mobilizava um intenso trânsito de gado através do centro de Londres. Outros relatos menos literários acerca da presença de abatedouros no espaço urbano também destacaram este tipo de confusão, acrescentando-lhe a sujeira causada pelo sangue, o mau cheiro, a fumaça das caldeiras (que ferviam ossos, vísceras etc.) e o barulho infernal do trotar dos rebanhos. ${ }^{15}$

Esta visão tem sido muito realçada por vários pesquisadores que exploram o tema, e geralmente é recuperada como parte importante da explicação sobre as pressões sofridas pelos açougueiros a partir do final do século XVIII. A este respeito, o geógrafo Ian MacLachlan evoca um panfleto datado

14 CARLYLE, apud PORTER, Roy. London, a social history. 4. ed. Harvard University Press: 2001, p.194. 15 MACLACHLAN, Ian. A bloody offal nuisance: the persistence of private slaughter-houses in nineteenthcentury London. Urban History, v. 34, n. 2, 2007. p. 227-254. 


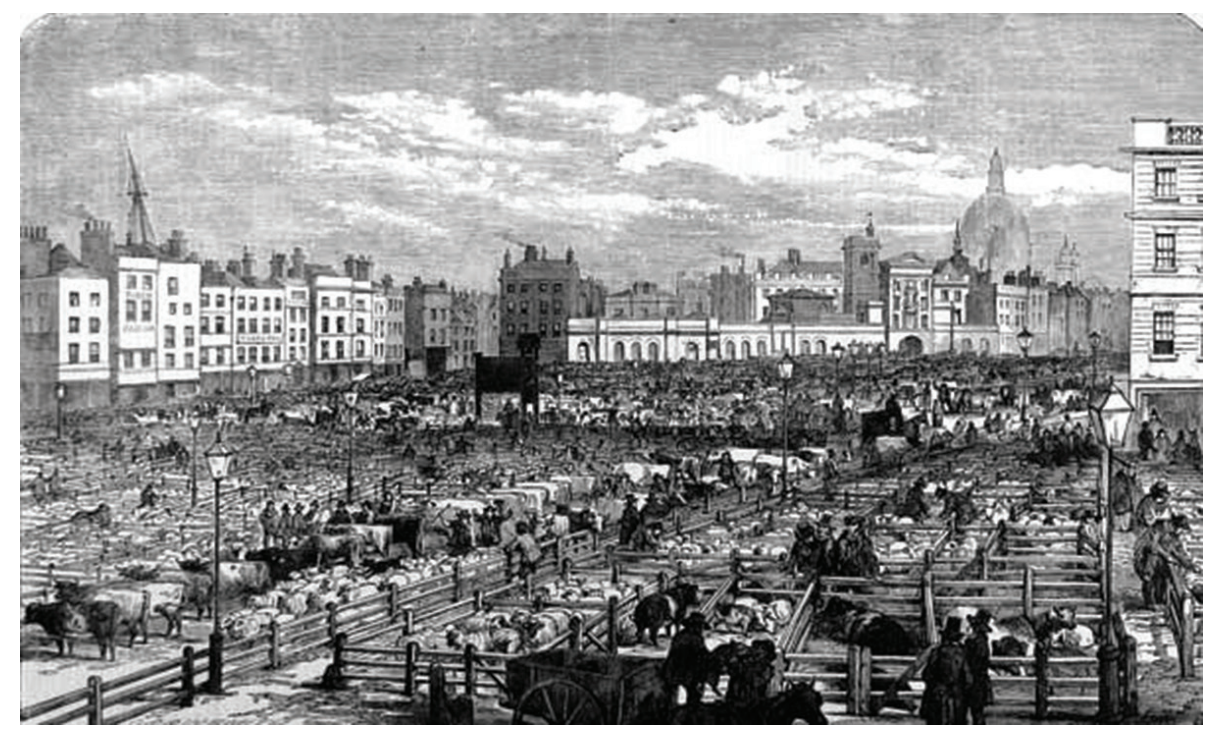

Figura 1: Mercado de Carne de Smithfield, Londres. Fonte: jornal London News, 1855. Extraído de: http://www.philological.bham.ac.uk/hosp/market.gif. A imagem destaca os rebanhos que eram negociados com os açougueiros.

de 1784 que reclamava contra os transtornos provocados por pequenos abatedouros privados instalados na cidade de Edimburgo, na Escócia, e como sua presença causava uma má impressão aos visitantes: "Os abatedouros, em sua situação atual, são considerados correta e justamente como os mais repugnantes estorvos que sempre desgraçaram a capital do reino; podem ser avistados da New Bridge e da Prince's Street". ${ }^{16}$

Estes argumentos ganharam fortes aliados à medida que os açougueiros, suas práticas e seus abatedouros, foram responsabilizados por diversas doenças transmitidas pela carne. A este respeito, a historiadora Dorothee Brantz mencionou o crescente medo de se contrair doença através de carne contaminada. ${ }^{17}$ As autoridades sanitárias começaram a desconfiar que algumas epidemias no final do século XVIII poderiam estar relacionadas ao consumo de carne deteriorada ou contaminada, mas tal conexão não ultrapassava o nível da especulação devido ao restrito conhecimento acerca de vermes

16 MACLACHLAN, Ian. The greatest and most offensive nuisance that ever disgraced the capital of a kingdom: The slaughterhouses and shambles of modern Edinburgh". Review of Scottish Culture. n. 17, 2005 p. 57-71.

17 BRANTZ, Dorothee. Animal Bodies, Human health, and the Reform of Slaughterhouses in NineteenthCentury Berlin. In: LEE, P. Y. (Org.). Meat, Modernity, and the Rise of the Slaughterhouse. Durham, New Hampshire: University of New Hampshire Press, 2008. p. 71-85. 
e de outros tipos de parasitas que se passaram por invisíveis até a invenção e uso do microscópio. Foi o caso da triquino (ou Trichina Spiralis), um verme presente na carne de porco que podia ser transmitido caso a carne não fosse bem cozida ou frita. De qualquer modo, como sintetizou Dorothee Brantz,

Desde que a carne se originava de um organismo vivo ela era um alimento volátil. Ela era muito nutritiva, mas também potencialmente perigosa; não somente podia apodrecer, mas ela poderia transmitir doenças insuspeitas para os consumidores humanos. Para minimizar tais danos, a produção de carne tinha que ser supervisionada na sua fonte: o abatedouro. ${ }^{18}$

A infecção provocada pelo consumo de carne contaminada ou deteriorada não era incomum antes do século XVIII. Porém, os meios para detectar a razão de tais moléstias, principalmente as gastrointestinais, não tinham ainda sido desenvolvidos. Além disso, tais doenças não atingiam grandes contingentes de pessoas devido a um moderado consumo de carne. Os pequenos abatedouros passaram a ser vistos como um problema à medida que sua atividade tornou-se mais intensa e volumosa, gerando transtornos como o trânsito dos rebanhos pelas ruas das cidades, o barulho, o mau cheiro, a sujeira e também a ameaça de contaminação.

Não obstante se pudesse notar regiões especializadas na criação de gado para corte desde os séculos XIV e XV na Europa, vinculadas ao maior consumo de carne nas cidades, o tamanho dos rebanhos não se comparava ao que se viu no fim do século XVIII e ao longo do século XIX.${ }^{19} \mathrm{Em}$ Paris, uma das maiores e mais populosas cidades europeias desde o século XVI, o número de açougueiros evoluiu mirrados 21\% (de 195 para 237)entre 1650 e 1701, enquanto cresceu 55\% (de 237 para 368) entre 1701 e $1782 .{ }^{20}$ A Londres de 1850 também teve o consumo per capita de carne dobrado em relação a 1750, saltando de 31 quilos para 69 quilos. Tal variação praticamente acompanhou o incremento populacional que foi de 1,1 milhões de habitantes em 1801 para 2,3 milhões em $1850^{21}$. Esta tendência também foi encontrada no Novo Mundo, em cidades do centro-oeste americano

18 BRANTZ, Dorothee. Animal Bodies, human health, and the reform of slaughterhouses in nineteenthcentury Berlin. In: LEE, P. Y. (Org.). Meat, modernity, and the rise of the slaughterhouse. Durham, New Hampshire: University of New Hampshire Press, 2008. p. 71-85.

19 HEERS, Jacques. O Ocidente nos séculos XIV e XV: Aspectos Econômicos e Sociais. São Paulo: Editora Pioneira/ Edusp, 1981. p. 104-105.

20 WATTS, Sydney. The Grande Boucherie, the "right" to meat, and the growth of Paris. In: LEE, P. Y. (Org.). Meat, modernity, and the rise of the slaughterhouse. Durham, New Hampshire: University of New Hampshire Press, 2008, p.13-26.

21 MACLACHLAN, Ian. "A bloody offal nuisance: the persistence of private slaughter-houses in nineteenth-century London". Urban History, v. 34, n. 2, 2007. p. 227-254. 
como Chicago e Cincinnati. Em 1866 Chicago já assustava com seu rebanho de 1,5 milhões de animais encurralados para o abate. ${ }^{22}$

Este crescimento certamente amplificou o impacto sobre o trabalho dos açougueiros nas cidades. Tal situação foi utilizada para justificar ações fiscalizadoras e punitivas do Estado sobre as práticas dos açougueiros, e neste contexto cresceu a presença e a força de diversos reformadores que advogavam cidades mais limpas, arejadas e modernas, adequadas a novas exigências de higiene e saúde. E para os reformadores (principalmente médicos e engenheiros que repercutiam ideias críticas ao Antigo Regime) deveria instituir-se o controle público sobre a produção e distribuição da carne. Mais do que isso, o abate deveria ser removido do convívio e do olhar humano. A resposta seria encontrada nos matadouros públicos.

Embora Paris já contasse com matadouros públicos desde 1818, esta instituição é um produto histórico do século XIX. Sua imposição contra as práticas dos açougueiros não foi fácil e nem automática. De modo geral, recaiu sobre os açougueiros uma fiscalização que passou a inibir seu trabalho sob a insígnia de "abatedouros clandestinos". Um pouco menos no mundo anglo-saxão, os abatedouros privados foram bastante fustigados e pressionados pela fiscalização e por uma política de remoção da matança de animais para longe do centro urbano, dentro de matadouros públicos. Friedrich Engels, um observador atento do mundo do trabalho da Inglaterra do XIX, deixou registros sobre esta "limpeza" ressaltando a punição sobre os açougueiros:

A 6 de janeiro de 1844 (se não me engano), houve uma sessão do tribunal de comércio de Manchester no decurso da qual foram condenados onze açougueiros por terem vendido carne imprópria para consumo. Cada um deles possuía ainda um boi ou um porco inteiro, ou vários carneiros ou ainda 20 ou 30 quilos de carne que foram apreendidos, tudo no mesmo estado. (...) Dois açougueiros de Wigon, dos quais um já tinha sido acusado pelo mesmo delito anteriormente, foram condenados a duas e quatro libras esterlinas de multa por terem posto à venda carne imprópria para consumo. (...) Numa mercearia de Bolton foram apreendidos vinte e seis presuntos estragados que foram queimados publicamente; 0 comerciante foi condenado a uma multa de 20 shillings. ${ }^{23}$

A carne vendida sempre foi alvo de fiscalização. Na Roma antiga, por exemplo, a carne era inspecionada e caso mostrasse sinais de cortes suspeitos ou de apodrecimento era confiscada e descartada, sem, contudo, haver

22 PACYGA, Dominic A. Chicago: Slaughterhouse to the world. In: LEE, P. Y. (Org.). Meat, modernity, and the rise of the Slaughterhouse. Durham, New Hampshire: University of New Hampshire Press, 2008. p. 154. 23 ENGELS, Friedrich. A Situação da classe trabalhadora na Inglaterra. 2. ed. São Paulo: Global, 1988. p. 82-83. 
punição ao vendedor. O que tornou a fiscalização do século XIX representativa foi a exposição pública do acontecimento, tanto no jornal quanto na punição. Porém, não se tratava apenas de deslocar a atividade dos pequenos abatedouros privados para um mesmo lugar. Na mesma Manchester observada por Engels, Sir James Philips Kay-Shuttleworth (médico inglês e reformador renomado) argumentou em 1832 que o problema não residia somente em remover o abate para um único matadouro ou obrigar os açougueiros a abater seus animais lá. O novo espaço deveria conter um tipo de planta produtiva que reconfigurasse o abate de maneira a eliminar a contaminação e possíveis focos de infecção de modo a promover a saúde pública. ${ }^{24}$

A proposta de matadouros públicos também foi encampada por reformistas humanitários que opunham severas críticas às formas de abate dos animais tidas todas como cruéis. Ao se pautar um debate sobre a dor e o sofrimento causados pelos açougueiros - e seus velhos métodos - buscava-se encaminhar uma solução em que a morte de animais com a finalidade de produzir alimentos, embora necessária, deveria ser um ato suave. Diversas entidades surgiram no século XIX defendendo tal ideia, como a Sociedade Real para a Prevenção da Crueldade dos Animais (RSPCA), criada em 1824, na Inglaterra, e sob o patronato da rainha Vitória desde 1840. Isto significava também que àquela altura o abate passava a ser abordado como um ato cruel e violento, tornando-se uma questão moral, vitoriana. ${ }^{25} \mathrm{O}$ açougueiro fora transformado numa espécie de inimigo dos animais de tal modo que seu trabalho e a finalidade da carne que vendia eram completamente abstraídos. Esta abordagem ganhou muito terreno ao ponto de extrair reclames de açougueiros sobre a sistemática campanha realizada contra eles, a exemplo do que foi publicado no número 297 da Revista do Comércio de Carne, de janeiro de 1894:

24 KAY-SHUTTEWORTH, James. The Moral and Physical Condition of the Working Classes of Manchester in 1832. Disponível em: <http://www.historyhome.co.uk/peel/p-health/mterkay.htm>. Acesso em: 10 jan. 2011.

25 Este debate também repercutiu no Brasil, nos últimos anos da capital do Império. Segundo artigo publicado na Gazeta de Notícias, no dia 2 de janeiro de 1882, o método de abate de bois no recéminaugurado Matadouro Santa Cruz, no Rio de Janeiro, era bárbaro: “A prova d'isso tivemola ainda agora na desagradavel impressão que deixou nos circunstantes a experiencia da matança executada por ocasião da inauguração do novo matadouro de Santa Cruz. Vibrar com o machado golpes sobre golpes sem chegar a abater completamente a victima, prolongando-lhe assim muitas vezes o doloroso supplicio, como a principio se praticava aqui; ou então enterrar na nuca com mão incerta um estylete, o qual nem sempre vai ferir com precisão o nó vital, como se faz hoje, são processos que não podem senão causar a mais horrível impressão áquelles que, por curiosidade ou por dever, assistem a taes espectaculos. (...)". Cf. DIAS, Juliana V.G. O Rigor da morte: a construção simbólica do "Animal de Açougue" na produção industrial brasileira. 2009. 107 f. Dissertação (Dissertação em Antropologia) - Programa de Pós-Graduação em Antropologia Social, Universidade Estadual de Campinas, Campinas, 2009, p.7. 
Eu sei que o povo não me trata como uma criatura imunda; e para falar sobre a "profunda degradação da natureza de toda a classe de homens", eu posso dizer que o povo não deturpa a mim e aos outros açougueiros, e que eu cumpro o meu dever e sou tão honesto quanto esses vegetarianos que fingem que só querem abolir os abatedouros privados, embora tudo o que eles desejam é que todos nós paremos de comer carne. Nós não somos uma escória e nunca fomos. ${ }^{26}$

Um dos resultados deste debate materializou-se em inúmeras técnicas que propuseram uma morte menos traumática e dolorosa. A carga contra os açougueiros era pesada. O apelo contra a crueldade do abate vinha também de reflexões filosóficas, como a do famoso reformador Jeremy Bentham que, ao afirmar a incapacidade de os animais processarem a experiência da morte "nos termos de uma agonia metafísica" - como os humanos -, transferia para os homens a responsabilidade da dor causada pela morte por abate. ${ }^{27}$

O matadouro público foi a solução histórica que prevaleceu naquela conjuntura, mas não apresentou-se como uma resposta a todos os problemas que vinham sendo discutidos. A questão da morte dolorosa permaneceu sem solução, ao menos à altura do que pensavam os militantes em defesa dos animais. Diferentemente disso, os matadouros públicos, uma vez edificados, nasceram como o lugar autorizado da morte de bois, porcos, cavalos e ovelhas. Os matadouros significaram também uma forma de esconder a morte em massa de animais dentro de uma realidade histórica em que o consumo de carne, principalmente nas grandes cidades, aumentava ano a ano. Sobre isso, a partir de um olhar mais panorâmico acerca desta conjuntura, a historiadora Paula Young Lee concluiu, com razão, que "os matadouros foram uma invenção para eliminar o horror mundano encontrado na matança feita nas ruas deslocando-o para a periferia urbana, onde a geometria do sistema da matança poderia se expandir sem restrições". ${ }^{28}$

A geometria à que se referiu Paula Y. Lee se fazia a partir de uma determinada divisão e especialização do milenar trabalho do açougueiro. Os matadouros públicos eram grandes plantas produtivas se comparadas aos maiores açougues da época, e foram pensados com o objetivo de separar as eta-

26 MACLACHLAN, Ian. Humanitarian Reform, Slaughter Technology, and Butcher Resistance in Nineteenth-Century Britain. In: LEE, P. Y. (Org.). Meat, Modernity, and the Rise of the Slaughterhouse. Durham, New Hampshire: University of New Hampshire Press, 2008. p. 111.

27 BENTHAM, Jeremy. A Utilitarian View. The Principles of Morals and Legislation, 1789, cap. 17, seção I. Disponível em: <http://www.animal-rights-library.com/texts-c/bentham01.pdf>. Acesso em: 12 jan. 2011.

28 LEE, P. Y. (Org.). Meat, Modernity, and the Rise of the Slaughterhouse. Durham, New Hampshire: University of New Hampshire Press, 2008. p.6. 
pas do trabalho em instalações específicas e articuladas entre si. A rigor os matadouros contavam com currais de madeira em sua parte externa, com a função de receber e abrigar os rebanhos que seriam abatidos. Destes currais os animais eram levados para outro cercado menor que se ligava a um corredor, também feito de cercas de madeira, que conduzia às salas de abate onde bois eram imobilizados e sangrados. Depois disso, a carcaça era suspensa e presa a ganchos e correntes, seguindo para outra sala para ser esfolada e cortada. Uma vez "depurado" o produto, a fiscalização inspecionava a carne. Os matadouros precisavam de água corrente para a limpeza e o descarte dos restos, incluindo o sangue. E a característica principal: deveriam ficar distantes do centro urbano. Para a historiadora Chris Otter, "o matadouro era uma tecnologia de vitalidade social, uma máquina de extermínio higiênica, garantindo que apenas carne saudável e saborosa atingisse o público", ${ }^{29}$ um aparato técnico que compelia a sociedade a esquecer de seus aspectos sangrentos, tornando-os praticamente invisíveis.

Pensado como máquina, o matadouro limpou as cidades de parte do trabalho dos açougueiros, aquela que entupia as ruas com o trânsito de animais, o maucheiro, o sangue e o barulho, avançando na conversão dos açougues em lojas asseadas de venda de carne. Esta batalha contra as práticas consideradas imundas e insalubres cruzaria grande parte do século XX, até que a presença do açougueiro se tornasse recessiva e cedesse lugar aos matadouros modernos, os frigoríficos. Até lá, o matadouro funcionou como uma instituição que deveria abrigar o abate em escala dos animais e mantê-lo distante do olhar público. Ao fazer isto, preservou-se também o estigma atribuído aos açougueiros por diversos reformadores que atuaram durante os séculos XIX e XX, julgando o trabalho do abate como sujo e marginal.

Cabe ressaltar que a pressão exercida pelo Estado sobre os açougueiros, a despeito de não ter se desenrolado numa mesma velocidade e intensidade em todos os lugares, produziu efeitos diferentes, chegando a favorecer os açougueiros em determinados casos. No Brasil, por exemplo, a instituição dos matadouros municipais veio acompanhada de uma fiscalização que se fez também contra a venda clandestina de carne verde, inviabilizando as atividades de pequenos criadores que complementavam sua renda com a venda de carne.Neste contexto de mudanças, estabelecer como obrigação o abate no matadouro municipal fazia com que pequenos criadores tivessem suas rendas diminuídas ou, numa hipótese um pouco pior para eles, tivessem seus animais vetados pela inspeção municipal. Impor que os abates

29 OTTER, Chris. The vital city: public analysis, dairies and slaughterhouses in nineteenth-century Britain. Cultural Geographies, v. 13, n. 4, 2006. p. 528. 
fossem todos feitos no matadouro equivalia a identificar com maior precisão o plantel bovino dos municípios de modo a reduzir a sonegação fiscal. Além disso, tal regulamentação bombardeava práticas populares de acesso às carnes verdes, instituindo novo costume que, a depender dessas circunstâncias, poderia beneficiar os donos de açougue.

O certo é que este tipo de ação do Estado alterou as práticas dos açougueiros, removeu o abate feito a céu aberto nas ruas da cidade, mas não fez desaparecer esta atividade. Na Londres do final do século XIX, a legislação de caráter higienista fixou limites à matança dos rebanhos, interceptando animais doentes ou suspeitos, e dificultou ao máximo a compra de gado estrangeiro. Porém, estas medidas, embora duríssimas para os açougueiros, não foram responsáveis pelo declínio que se viu entre 1870 e 1905, quando os pequenos abatedouros licenciados diminuíram de 1500 para menos de 400, ainda que o consumo de carne tivesse aumentado naquele período. ${ }^{30}$

Uma observação aparentemente secundária registrada por Ian MacLachlan a respeito da redução dos açougueiros que atuavam em Londres torna-se reveladora sobre a principal razão que levou ao quase completo desaparecimento dos pequenos abatedouros e à desativação da maioria dos matadouros públicos na segunda metade do século XX: "as importações de carne resfriada e congelada cresceu rapidamente de 1875 a 1895, que substituiu o abate de gado importado". ${ }^{31}$ A sobrevivência dos açougueiros (e seu modo de trabalhar) foi definitivamente ameaçada pela industrialização da carne, convertida em mercadoria fabril e massificada.

Ainda que tardia, se comparada a outros ofícios, a industrialização da carne, iniciada no final do século XIX, minou a existência de açougueiros. Engatilhada à acumulação de capital, a carne industrializada transformar-se-ia cada vez mais em um de seus principais motores. Os tempos atuais, conforme criticou o artista de quadrinhos Joe Sacco, quando "a carne chega do abatedouro dentro dessas embalagens de isopor, seladas com etiquetas de peso, preço e informação sobre o produto, picadinha, impossível de reconhecer", ${ }^{32}$ alicerçaram-se historicamente no processo de industrialização da carne. E este mesmo processo modificou nossa sensibilidade face ao que comemos. Não há mais açougueiros como no passado e nem rebanhos inteiros trotando ruidosamente em ruas que se encherão de sangue, fedor e

30 MACLACHLAN, Ian. A bloody offal nuisance: the persistence of private slaughter-houses in nineteenthcentury London. Urban History, v. 34, n. 2, 2007. p. 227-254, p. 246-248.

31 Idem, p. 247.

32 SACCO, Joe. Derrotista. São Paulo: Conrad, 2006. p.56. 
sujeira. Conforme a visão insuspeita de Steven E. Sanderson, presidente da Sociedade de Preservação dos Animais Selvagens (WCS),

Nós agora estamos frente a uma época em que a carne sobre a mesa dos consumidores terá sido desenvolvida na Europa e nos USA, criada na América Latina, alimentada com grãos exportados... Abatida sob padrões internacionais e consumida em lugares muito distantes do seu ponto de origem. ${ }^{33}$

Faltou dizer: a custa de muito trabalho barato. Cabe-nos agora, por fim, explorar e explicar esta dimensão da produção da carne.

\section{TECNOLOGIA, LOGÍSTICA E TRABALHO BARATO: O CINTURÃO DA CARNE DO NOVO MUNDO}

O congelamento da carne e seu transporte nesta condição representaram um grande avanço tecnológico para o comércio deste produto. A carne era produzida em toneladas, empacotada, congelada, transportada e vendida. Isto se tornou viável na segunda metade do século XIX, mas não se converteu imediatamente em uma prática generalizada. O transporte refrigerado foi inicialmente desenvolvido pelos matadouros de Chicago, na década de 1870, liderados pela Swift e Armour. Tal incremento tecnológico possibilitou a criação de um mercado interno para a carne e derivados que nocauteou os pequenos abatedouros espalhados no país. Chicago, Cincinnati, St. Louis e Kansas City formaram um verdadeiro cinturão da carne no final do século XIX. As mercadorias eram distribuídas a partir de uma rede ferroviária já bastante capilar no século XIX. Escorados neste esquema os grandes matadouros abriram lojas próprias em cidades do leste do país, uma vez que muitos açougueiros negavam-se a vender a carne produzida em Chicago.

Até o começo do século XX esta próspera indústria foi mostrada como motivodeorgulho nacional, umafilha deseutempo, estruturadaemmoldesimperialistas. Suainternacionalização fez-se rapidamente na direção da América do Sul, onde estabeleceu suas principais filiais. De lá enviava charque e enlatados para países europeus e os Estados Unidos, principalmente no contexto da Segunda Grande Guerra. ${ }^{34}$ Some-se a isto a formação de um fortíssimo truste cujo paradigma foi contemporâneo à famosa Standart Oil.

33 GOUVEIA, Lourdes. Global Strategies and Local Linkages: The case of the U.S. Meatpacking Industry. In: BONANNO, A. et al. From Columbus to ConAgra: The Globalization of Agriculture and Food. Lawrence/ Kansas: University Press of Kansas, 1994. p.129.

34 Somente a Swift, instalada no sul do Brasil, exportou mais de nove toneladas de carne processada em 1939. 
Um dos primeiros olhares dissonantes sobre esta indústria, cuja repercussão incomodou até o presidente Roosevelt, veio de Upton Sinclair, um escritor que entrevistou trabalhadores ocupados em matadouros na cidade Chicago durante 1904 a fim de publicar uma matéria no semanário socialista Appeal to Reason. A documentação produzida mostrou-se tão chocante que sustentou um livro, editado em 1906, cuja narrativa sobre a situação dos trabalhadores na indústria da carne forçou o governo federal a determinar uma investigação a respeito daquela indústria. ${ }^{35} \mathrm{Em}$ passagem singular, Sinclair conta o que viu dentro dos matadouros:

Havia quinze ou vinte bois nos currais e era uma questão de um par de minutos para golpeá-los e rolá-los para fora. Então uma vez mais os portões eram abertos e outro lote era introduzido apressadamente. (...) A maneira com que os trabalhadores faziam isto era alguma coisa que se via e nunca mais se esquecia. Eles trabalhavam com intensidade furiosa, literalmente correndo - numa passada que não havia nenhuma comparação, exceto com uma partida de futebol. O trabalho era altamente especializado, cada homem tinha sua tarefa para fazer; geralmente isto consistia em dois ou três cortes específicos que ele fazia em quinze ou vinte carcaças de bois, numa linha. Primeiro vinha o "açougueiro", para sangrá-las; isto significava um rápido golpe, tão rápido que você não conseguia vê-lo - somente o lampejo da faca; e antes que você pudesse perceber aquilo, o homem já tinha disparado para a próxima na linha, e uma torrente de sangue vivo escorria pelo chão. Este chão estava coberto com 1,5 centímetros de sangue, a despeito dos melhores esforços dos homens que tentavam removê-lo com pás. ${ }^{36}$

O que Sinclair descreve é um sistema industrial de "desmontagem". O próprio Henry Ford disse ter conhecido tal sistema quando visitou os matadouros de Chicago, e aplicou o que viu lá em 1913, na primeira experiência com a montagem de carros numa linha de produção: “Tratava-se da montagem de magnetos. (...) Creio que esta estrada [linha] móvel foi a primeira que já se construiu com este fim. Veio-me a ideia vendo o sistema de carretilhas aéreas [nórias] que usam os matadouros de Chicago". ${ }^{37}$

Nesta linha de desmontagem, a simplificação do trabalho (baseada em sua divisão) possibilitou a contratação de trabalhadores sem qualificação,

35 KOLKO, Gabriel. Meat Inspection. Theory and Reality. The Triumph of Conservatism: A Re-interpretation of American History, 1900-1916. Nova York: The Free Press, 1963. p. 98-112. Disponível em: <http:// us.history.wisc.edu/hist102/readings/>. Acesso em: 12 nov. 2011.

36 SINCLAIR, Upton. The Jungle. Harmondsworth: Penguin Modern Classics, 1965. p. 48-49.

37 FORD, Henry. Os Princípios da Prosperidade. Tradução de Monteiro Lobato. 2. ed. Rio de Janeiro: Livraria Freitas Bastos, 1964. p. 65-66. 
o que viabilizou uma política salarial barata. Este foi, desde o começo dessa indústria, o pilar central que sustentou a trajetória bilionária da indústria da carne. Pressionados a aceitar péssimas condições de trabalho, os imigrantes, recém- chegados da Europa, povoaram os frigoríficos estadunidenses.

Poloneses e lituanos eram maioria, e o pouco ou nenhum domínio da língua inglesa os tornava presas fáceis para os matadouros. Juntos a trabalhadores alemães, irlandeses, italianos e de outras nacionalidades em menor número, eles formaram um volumoso exército industrial de reserva que fazia fila às portas dos grandes matadouros em Chicago.

Em meio a essa multidão, os representantes dos frigoríficos saíam a recrutar os mais fortes e aparentemente qualificados, sem qualquer negociação acerca de salários ou jornada de trabalho. Apenas diziam: "Venham!". A produtividade também estava calcada na fartura de mãodeobra. Em 1904, num dos grandes frigoríficos de Chicago, 230 trabalhadores abatiam e processavam 105 bois por hora. Com tantos homens e mulheres aguardando trabalho naqueles frigoríficos a produção per capita era definida dia a dia. $\mathrm{O}$ pagamento seguia a mesma lógica e oscilava dentro de uma escala de vinte taxas diferentes, variando de 16,5 a 50 centavos de dólares por hora. ${ }^{38}$

As diferenças entre tantas nacionalidades, muitas vezes transformadas em rixas pessoais, dificultavam a organização sindical e repetiam um recurso já velho conhecido do capital naquele país, que fora fundamental para alavancar o capitalismo. Estimular a imigração de trabalhadores pobres era um método, e contava com a forte intervenção do Estado para viabilizar o transporte dessa mercadoria.

Durante a crise dos anos 1930, John Steinbeck percebeu que este método esteve ativo desde, pelo menos, o século XIX, quando chineses e hindus realizaram a construção das ferrovias estadunidenses, e quando mexicanos povoaram os campos californianos para trabalhar até oporem algum tipo de resistência organizada e serem substituídos por uma nova leva de importados, os filipinos..$^{39}$ Este método se reforçava ainda com o trabalho de toda a família nos frigoríficos que, não raras vezes, era recrutada em bloco. A despeito de a lei, em certos estados, proibir o emprego de menores de quatorze anos, muitos pais induziam seus filhos a mentir sobre sua idade. Por fim, a

38 PACYGA, Dominic A. Chicago: Slaughterhouse to the World. In: LEE, P. Y. (Org.). Meat, Modernity, and the Rise of the Slaughterhouse. Durham, New Hampshire: University of New Hampshire Press, 2008. p.153166, p.156.

39 STEINBECK, John. Dubious Battle in California. America and Americans, and Selected Nonfiction. New York: Penguin Books, 2003. p.71-77. 
compressão salarial fazia que a sobrevivência de uma família dependesse do assalariamento de todos.

As condições de trabalho, e não só o ritmo, também eram bastante insalubres, e o fato ficou mais evidente e público em decorrência do livro de Upton Sinclair e do relatório Neill-Reynolds, elaborado por determinação do Departamento da Agricultura, logo após a repercussão causada por The Jungle. De um modo ou de outro, os autores do relatório sublinharam seus testemunhos sobre os sinais de sangue, dos restos de carne putrefata e "o cheiro da morte sistemática", construindo a partir disso o retrato das condições sanitárias que cercavam os matadouros daquela época. ${ }^{40}$

Tais condições históricas fertilizaram o crescimento de grandes companhias que iriam monopolizar o mercado da carne, particularmente durante o contexto da segunda Grande Guerra, quando a Europa aumentou substancialmente suas importações. Foi também a partir daquele momento que se definiu um novo modelo de produção e de consumo da carne,${ }^{41}$ estruturado numa nova divisão internacional do trabalho, na qual tal produção se concentraria principalmente nos Estados Unidos, Canadá e parte da América Latina.

A formação das gigantes Swift, Armour, Wilson e Cudahy nos Estados Unidos esteve completamente articulada a tais condições históricas, permitindo-lhes uma participação superior a 80\% no mercado interno até a década de 1950.0 padrão de consumo de carne naquele país tornou-se uma medida para grande parte do mundo e foi adotado à proporção que o preço da carne diminuía. Raciocinando em relação aos Estados Unidos, o consumo per capita de carne dobrou em cem anos, chegando a aproximadamente 100 quilos em 2002. Cabe ainda ressaltar que a taxa de lucro nesta indústria é das mais baixas, característica de uma produção em massa que opera escorada na intensificação do trabalho. ${ }^{42}$

40 KOLKO, Gabriel. Meat Inspection. Theory and Reality. In: The Triumph of conservatism: A re-interpretation of American history, 1900-1916. New York: The Free Press, 1963. p. 98-112. Disponível em: <http://us.history. wisc.edu/hist102/readings/>. Acesso em: 12 nov. 2011.

41 Embora não seja objetivo deste artigo discutir as mudanças nos padrões de consumo da carne, resumidamente registramos os quatro fatores principais que contribuíram sobremaneira para tal alteração: (i) o barateamento do preço da carne de boi, de suíno e de frango; (ii) novas necessidades e noções de higiene que modificaram a compreensão popular sobre o preconceito contra o consumo de carne abatida por outros; (iii) o desenvolvimento de uma logística que permitiu uma distribuição mais adequada (isto é, lucrativa); (iv) e o emprego de tecnologias que possibilitaram o congelamento da carne sem efeitos colaterais visíveis.

42 Durante a década de 1990, de cada 100 dólares faturados na produção de carne de boi 93 dólares eram gastos com custos. Cf. FITZGERALD, Amy J. A Social History of the Slaughterhouse: From Inception to Contemporary Implications. In: Human Ecology Review, v. 17, n. 1, 2010. p. 58-69, p. 62. 
A este processo de industrialização correspondeu o desenvolvimento de uma cadeia produtiva, monopolizada por poucas empresas e basicamente dividida em etapas justapostas, especializadas (i) no melhoramento genético dos animais, (ii) na produção dos insumos, (iii) na produção da carne viva e (iv) no seu processamento. Com isso combinou-se o emprego de trabalhadores baratos com investimentos em ciência e tecnologia, algo que permitiu a redução do prazo de engorda dos animais e o melhor aproveitamento das rações. ${ }^{43}$

Finalmente, no que se refere à etapa de processamento da carne realizada nos frigoríficos, pode-se dizer que a tecnologia não modificou o trabalho desde a inauguração da indústria da carne. Em síntese, esfolar e retalhar bois, porcos e aves ainda requerem um tipo de trabalho considerado difícil e intensificado. De um lado estão os animais a serem desmontados. De outro estão os trabalhadores, manejando serras e facas. Sobre isso, têm razão o antropólogo Michael Broadway e o geógrafo Donald Stull quando argumentam que a mudança no trabalho executado nos frigoríficos deu-se por sua crescente intensificação, a despeito de todo incremento tecnológico existente. ${ }^{44}$ Em qualquer caso que se busque observar, o que se vê desde os tempos de Upton Sinclair são trabalhadores tão completamente expropriados que se sentem pressionados a aceitar condições de trabalho cada vez mais precárias. Certamente este é um importante problema para a pesquisa histórica que aqui tentei sublinhar.

Nesse mesmo sentido, a partir da década de 1960 os grandes frigoríficos de abate de bois e de porcos (e os recém-criados frigoríficos de aves) começaram a transferir suas plantas produtivas para regiões interioranas, onde houvesse vantagens fiscais para sua instalação, o suprimento de animais e de água fosse farto e os trabalhadores não tivessem uma tradição sindical questionadora e combatida. O resultado desta reestruturação agigantou ainda mais os frigoríficos e manteve o trabalho intensamente explorado e barato como elemento central nesta equação, mas esta é outra história.

430 caso do frango é exemplar desta evolução tecnológica. Atualmente o peso do frango para abate é de 2,44 quilos, mas já foi de 2,25 quilos em 2000, 1,9 em 1990, 1,8 em 1980, 1,7 em 1970, 1,6 em 1960 e 1,5 em 1930. Na década de 1940 um frango ou uma galinha viviam 3,5 meses até a degola. Vinte anos depois este tempo foi reduzido para dois meses até encolher à casa dos 41 dias em 2009.

44 STULL, D.D. \& BROADWAY, M.J. Killing them softly. Work in meatpacking plants and what it does to works. In: Any Way You Cut It. Meat Processing and Small-Town America. Lawrence, Kansas: University Press Kansas, 1995. p. 61-83. 


\section{CONSIDERAÇÕES FINAIS}

Convém agora tomar alguma distância a fim de avaliar este processo histórico. A industrialização da produção de carne disseminou o consumo desta mercadoria ao torná-la mais barata, e isto se deu à custa da simplificação e divisão do trabalho do açougueiro e de duas "reestruturações produtivas".

A primeira, que procurei discutir aqui, ceifou o domínio dos açougueiros sobre o universo da produção da carne. Uma insuportável pressão exercida pelos grandes matadouros sufocou e eliminou a existência dos açougueiros, tornando-a residual e recessiva na atualidade. Ato contínuo, a linha de "desmontagem" dos animais que inspirou Henry Ford triturou este antigo e milenar ofício e o reduziu a operações repetitivas, ao alcance de trabalhadores sem qualificação.

A segunda "reestruturação" criou uma imensa cadeia produtiva que articulou a geração, a produção, o abate e a distribuição da carne, apoiada em inovações tecnológicas e científicas que literalmente anabolizaram o crescimento e o tamanho dos animais; e tudo isto elevou a intensificação do trabalho a uma escala cuja regra tem sido a destruição física e mental dos trabalhadores.

A partir da síntese desses duzentos anos não encontrei termos favoráveis aos trabalhadores de frigoríficos numa comparação histórica com os açougueiros, ou mesmo com jornaleiros e aprendizes articulados ao ofício. Cortar carne nos frigoríficos não conferiu o mesmo tipo de prestígio e statusque estruturou a identidade dos açougueiros (uma identidade centrada no trabalho), e esta é uma conclusão importante que merece ser explorada e aprofundada noutros estudos.

A robusta identidade dos açougueiros parece ter dado lugar ao medo que os trabalhadores dos frigoríficos expressavam diante do desemprego e de certo desamparo político, conforme percebeu, por exemplo, Upton Sinclair no início do século XX. Naquele contexto, simbolicamente, a importância de São Bartolomeu se esvaiu de modo que cortar carne deixou de ser uma tarefa com algum reconhecimento e recompensa social.

Artigo recebido para publicação em: 20/07/2013

Artigo aprovado para publicação em: 21/02/2014 